\title{
Identification of Dwelling-specific Energy Saving Benchmarks from Building Stock Models
}

\author{
John Allison, Joe Clarke \\ Energy Systems Research Unit, University of Strathclyde, Glasgow, United Kingdom
}

\begin{abstract}
The evaluation of benchmarks for building energy savings for a specific dwelling usually requires the generation of an individually calibrated model (ICM). The development of such models requires specialist knowledge, has time and cost implications, and may require the deployment of field devices to obtain data for the calibration process. The project reported here compared the outcomes from the simulation of detailed ICMs and corresponding (simpler) models selected from a pre-constructed collection of models comprising a building stock. The results demonstrated a reasonable agreement between benchmarks derived from ICM and stock model simulations in $\sim 29 \%$ of cases. In the other cases, the stock model tended to over-predict the potential savings. This was attributed to lack of diversity in parameters defining heating system time-of-use and set-point temperatures.
\end{abstract}

\section{Introduction}

An upgrade programme, developed in co-operation with Glasgow City Council as part of a UK Future Cities Demonstrator project funded by Innovate UK (MRUK, 2016), set out to develop a low cost, rapid evaluation procedure for the assessment of housing upgrades when applied to dwellings throughout the City (Allison et al., 2015).

The procedure combines building simulation and field monitoring of indoor conditions and energy use. This paper describes the approach with the emphasis on the building simulation component and its use to provide benchmark data to quality-assure the upgrade outcome.

The aim of the paper is to investigate if a collection of stock models with sufficient parameter diversity can provide a useful benchmark prediction as judged by acceptable agreement with a calibrated dynamic model of a dwelling, i.e. an ICM.

While it is well understood that weather, archetype details (building type, number of bedrooms, floor area, construction and orientation), occupant behaviour, heating/ cooling systems type and control, social and economic influences and desired thermal comfort dictate dwelling energy use, most approaches to stock modelling encapsulate limited variability in occupancy and heating system use (Kavgic et al., 2010).

In a previous project (Clarke et al., 2008), the Scottish housing stock was represented as a collection of models as required by the ESP-r program. These models - representing the existing stock and the many possible upgrades that may be applied in future - were then presimulated and the results encapsulated within a Housing Upgrade Evaluator (HUE) tool. HUE therefore comprises a database of estimated energy use profiles (for space heating/ cooling, domestic hot water, lighting, and equipment use) derived from the results from simulating a large number of building simulation models. From a set of pragmatic inputs defining dwelling form, fabric and operation, the tool is able to determine the energy and emissions reduction potential of proposed upgrades applied to any portion of the building stock.

In contrast, when focussing on single dwellings, the evaluation of benchmarks for building energy savings typically requires the generation of an ICM for a specific dwelling. The development of such models requires specialist knowledge and has cost implication associated with the acquisition of calibration data from smart meters or other field devices. This paper establishes a procedure to simplify the process without unacceptable loss of accuracy. The procedure was trialled by application to dwellings scheduled for upgrade throughout Glasgow. This paper reports the following.

- The key parameters required to select suitable models from the collection representing the stock.

- The establishment of the ICM and the use of monitored data to enable its calibration.

- Comparison between benchmarks from selected models from the stock and the ICM.

\section{Glasgow City trial}

The Scottish House Condition Survey Local Authority Analysis 2014-2016 estimated that 27\% of dwellings in Glasgow City are in fuel poverty (Scottish Government, 2018). The Scottish Government has committed resources to tackle fuel poverty through various grants and other schemes, including the Home Energy Efficiency Programme for Scotland Area Based Schemes (HEEPS: ABS) (Scottish Government, 2016) and the Energy Companies Obligation (SI 2012/3018). This funding enabled Glasgow City Council to work with social property owners and private contractors to pursue insulation upgrades that would benefit those living in the most fuel-poor areas.

The work being carried out under HEEPS: ABS is external wall insulation as this measure allows the most significant energy saving per property, which is a central 
aim for the Scottish Government. External wall insulation was applied in the upgrade programme and all houses already had loft insulation.

To gain an overview of the upgrade quality and typical responses by occupants regarding behaviour adjustments, the dwelling selection process was based on random sampling within each city area corresponding to a 1/9th replicate subset. Table 1 provides details on the sample of the monitored dwellings discussed in this paper.

Table 1: Sample of dwellings included in the trial.

\begin{tabular}{|c|c|c|c|}
\hline ID & $\begin{array}{c}\text { Construction } \\
\text { type }\end{array}$ & $\begin{array}{c}\text { Building } \\
\text { type }\end{array}$ & Occupancy \\
\hline AN2 & \multirow{2}{*}{$\begin{array}{l}\text { 1950s/60s solid } \\
\text { concrete/ brick } \\
\text { high rise }\end{array}$} & $\begin{array}{l}\text { Flat, middle } \\
\text { floor }\end{array}$ & $\begin{array}{c}2 \text { adults (1 } \\
\text { working, } 1 \text { not), } \\
2 \text { children } \\
\end{array}$ \\
\hline AN3 & & $\begin{array}{l}\text { Flat, middle } \\
\text { floor }\end{array}$ & $\begin{array}{l}1 \text { adult (not } \\
\text { working) }\end{array}$ \\
\hline CA4 & \multirow{5}{*}{$\begin{array}{c}\text { 1920s terrazzo } \\
\text { block cavity } \\
\text { wall }\end{array}$} & $\begin{array}{l}\text { Semi- } \\
\text { detached, } 1 \\
\text { floor }\end{array}$ & $\begin{array}{l}2 \text { adults } \\
\text { (retired) }\end{array}$ \\
\hline CA5 & & $\begin{array}{l}\text { Semi- } \\
\text { detached, } 1 \\
\text { floor }\end{array}$ & $\begin{array}{c}2 \text { adults } \\
\text { (working) }\end{array}$ \\
\hline CA6 & & $\begin{array}{c}\text { Semi- } \\
\text { detached, } 1 \\
\text { floor } \\
\end{array}$ & $\begin{array}{c}3 \text { adults } \\
\text { (working), } 1 \\
\text { child }\end{array}$ \\
\hline CA7 & & $\begin{array}{l}\text { 4-in-a-block, } \\
\text { ground floor }\end{array}$ & 1 adult (retired) \\
\hline CA8 & & $\begin{array}{c}\text { Semi- } \\
\text { detached, } 1 \\
\text { floor }\end{array}$ & 1 adult (retired) \\
\hline DR1 & \multirow{5}{*}{$\begin{array}{l}\text { 1950s solid } \\
\text { brick wall }\end{array}$} & $\begin{array}{l}\text { Flat, middle } \\
\text { floor }\end{array}$ & $\begin{array}{l}2 \text { adults } \\
\text { (retired) }\end{array}$ \\
\hline DR2 & & Flat, top floor & $\begin{array}{c}2 \text { adults } \\
\text { (working) }\end{array}$ \\
\hline DR4 & & $\begin{array}{l}\text { Flat, ground } \\
\text { floor }\end{array}$ & $\begin{array}{c}3 \text { adults } \\
\text { (working) }\end{array}$ \\
\hline DR5 & & $\begin{array}{l}\text { Flat, ground } \\
\text { floor }\end{array}$ & $\begin{array}{l}2 \text { adults } \\
\text { (retired) }\end{array}$ \\
\hline DR6 & & $\begin{array}{l}\text { Flat, ground } \\
\text { floor }\end{array}$ & 1 adult (retired) \\
\hline SL3 & \multirow{2}{*}{$\begin{array}{c}\text { 1920s cavity } \\
\text { concrete panel / } \\
\text { brick }\end{array}$} & $\begin{array}{l}\text { Flat, ground } \\
\text { floor }\end{array}$ & 1 adult (retired) \\
\hline SL4 & & Flat, top floor & $\begin{array}{c}4 \text { adults } \\
\text { (working) }\end{array}$ \\
\hline SH6 & \multirow{3}{*}{$\begin{array}{c}\text { 1920s cavity } \\
\text { brick/ concrete } \\
\text { block }\end{array}$} & $\begin{array}{c}\text { Semi- } \\
\text { detached }\end{array}$ & 1 adult (retired) \\
\hline SH7 & & $\begin{array}{c}\text { Semi- } \\
\text { detached, } 1 \\
\text { floor }\end{array}$ & $\begin{array}{l}2 \text { adults } \\
\text { (retired) }\end{array}$ \\
\hline SH8 & & $\begin{array}{c}\text { Semi- } \\
\text { detached }\end{array}$ & $\begin{array}{c}2 \text { adults (1 } \\
\text { working, } 1 \text { not), } \\
1 \text { child }\end{array}$ \\
\hline
\end{tabular}

As shown, the selected properties encapsulate a variety of archetypes - semi-detached, tenement flat, multi-storey flat, and four-in-a-block - while constructions encompass solid brick, solid sandstone, solid concrete, and various two-leaf cavity types. The dwellings were mostly occupied by between one and three adults some of which were in full-time occupation, with some dwellings also having children.

\section{Upgrade evaluation procedure}

\section{Procedure overview}

Properties were sampled from the upgrade programme to trial the benchmarking procedure intended to enable the quality-assure of the energy use and indoor conditions (temperature and relative humidity) improvements resulting from the upgrade. This paper focuses on the energy use component of the trial. The indoor conditions monitoring is here only included for the purposes of model calibration and not for the assessment of satisfactory indoor conditions.

The assessment included a pre- and post-upgrade period, both falling within the same heating season. An initial deployment of monitoring equipment was undertaken at least 10 days before the upgrade works commenced. All monitoring was conducted with explicit consent from the occupants. All occupants were provided documentation that explained the nature and purpose of the monitoring equipment, the extent of the required access to their homes, and the analysis to be applied to the collected data. The measurement of heating energy consumption is not straightforward and can involve invasive sensor installations in pipework in the case of gas heating. To minimise occupant impact, utility meter readings were relied on as a proxy for heating energy consumption under the assumption that lighting and cooking energy use would be unaffected by the upgrade. The procedure uses monitored external conditions data to adjust the postupgrade heating energy consumption to ensure a fair comparison between the pre- and post-upgrade periods.

To determine the efficacy of the upgrade, the postupgrade energy consumption of the dwelling was compared to a benchmark, with the result indicating whether the expected performance improvement had been attained. A practical method to determine a benchmark is explicit dwelling simulation. In establishing such a benchmark, it is assumed that there is no behavioural change after the upgrade and that the upgrade is fault-free. The energy use evaluation used monitored external weather conditions to adjust the energy consumption after the upgrade to enable comparison with the pre-upgrade period. The percentage difference in dwelling energy use is then compared with an energy benchmark that is specific to the dwelling and obtained by modelling.

\section{Individually-calibrated models (ICM)}

The ESP-r simulation program (Clarke, 2001) was employed to establish an energy saving benchmark for each monitored dwelling. The following data are required for model creation.

- Dwelling geometry relating to the envelope and internal zoning.

- Construction details for fabric and glazing.

- Occupancy profile and related hot water, electrical appliance and lighting use. 
- Parameters of the heating system and related control settings.

Dwelling dimensions were obtained via inspection of architectural drawings provided by the Council (such as shown in Figure 1). An example of a resulting model is shown in Figure 2.
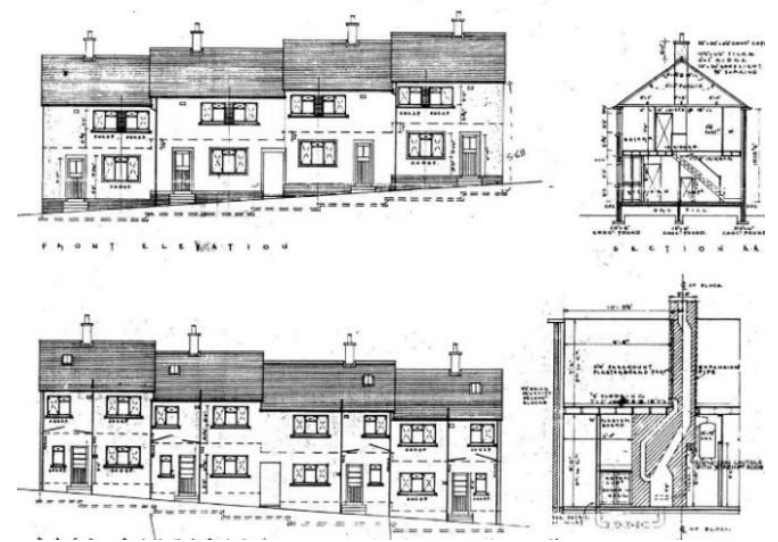

Figure 1: An architectural drawing as supplied by Glasgow City Council.

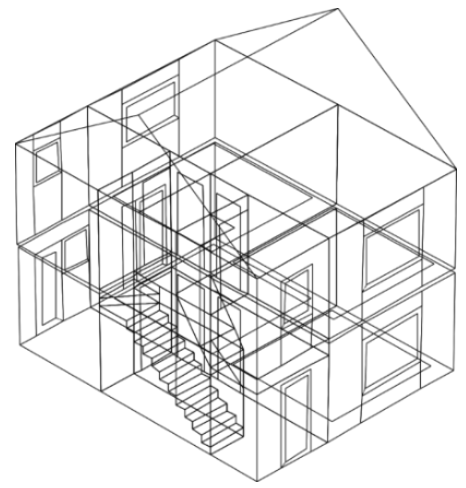

Figure 2: ESP-r dwelling model derived from architectural drawings.

Construction information was extracted from prior versions of the Building Regulations relevant to the year of construction and elsewhere (e.g. Harrison et al., 2015) for non-traditional housing types.

The ICMs utilise occupancy profiles generated using a stochastic model (Flett and Kelly, 2016 \& 2017). This models allows for the generation of diverse occupant presence/ behaviour and related electrical appliance, hot water and lighting use. These data that are then attributed to the ESP-r model.

The key parameters required to generate the profiles are as follows.

- Dwelling type: house or flat.

- Bedrooms: 1-4.

- Floor area (required for lighting model only).

- Household type and age: single adult, small family, single pensioner etc.

- Household tenure: owner-occupier, privately-rented, rented from housing associations, rented from Local Authorities.

- Availability of mains gas connection.

- Area type: urban, town, rural.
- Scottish Index of Multiple Deprivation (SIMD) - can be derived from income per week for postcode.

The information required was gathered from site visits and a questionnaire completed by occupants.

Figure 3 shows an example of an occupancy profile and related gains as generated by the model.

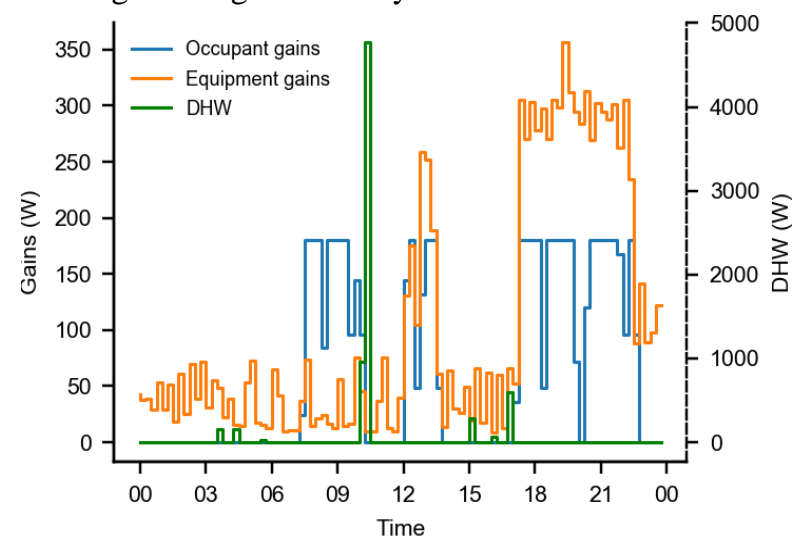

Figure 3: Example of a generated occupancy profile.

The parameters of the heating system controls - time of use and set-point temperatures - were determined from monitored indoor conditions data. The monitoring of indoor conditions required two wireless temperature and humidity sensors transmitting to a local, internetconnected logger/ router at 5-minutely intervals.

In each dwelling, the sensors were installed in a living room and utility area (kitchen or bathroom). A temperature/ humidity sensor was also deployed externally as a local, low cost weather station, with one station covering the monitoring needs for all dwellings in the immediate vicinity. The external conditions data is used for the weather-related adjustments of the measured energy consumption and the model calibration process. Figure 4 shows a sample of monitored data captured for a dwelling during the pre-upgrade period. Other weather data, such as solar irradiation and wind velocity were obtained from a local weather station.

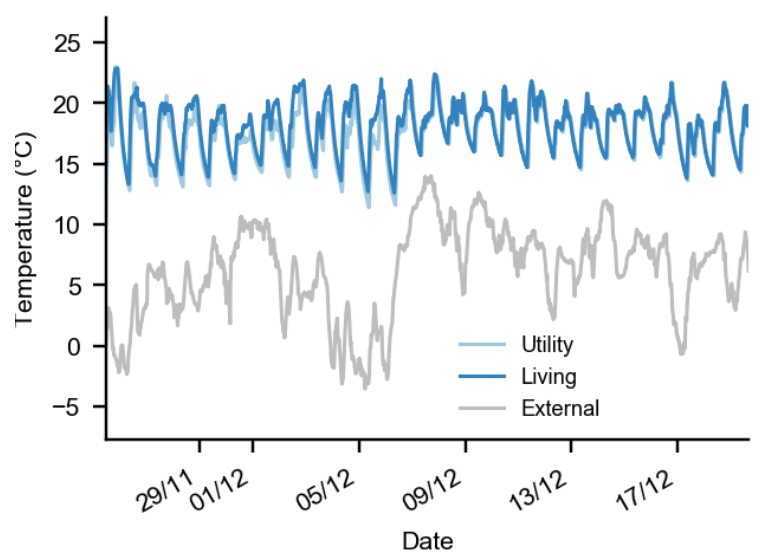

Figure 4: Monitored temperature data over a preupgrade period. 
It can be difficult to estimate heating system controls by direct inspection of data in the form of Figure 4. Instead, the data was transformed into the statistical representation as shown in Figure 5. This was generated by resampling

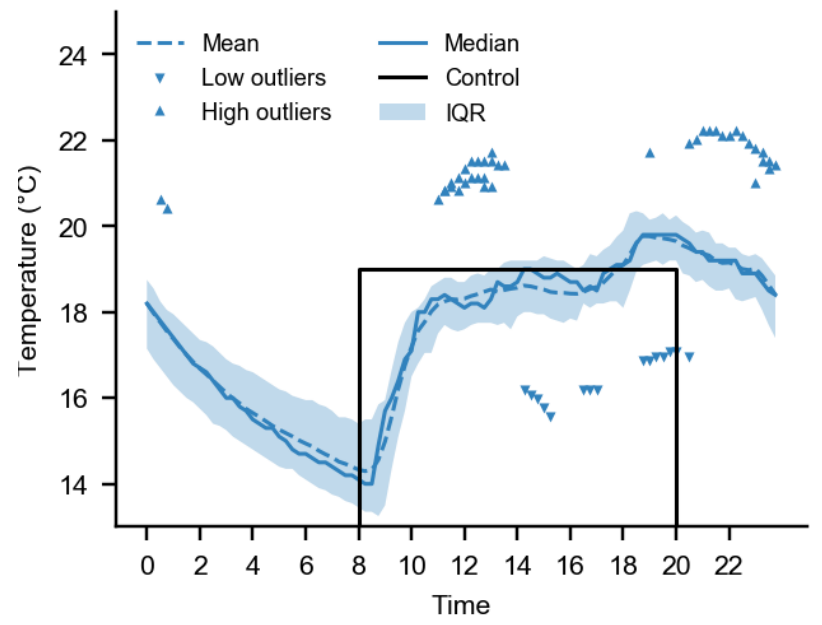

Figure 5: Statistical metrics of daily indoor temperatures and the identified heating control profile.

the monitored data to 15-minutely resolution and then calculating the descriptive statistics (mean, median and standard deviation) across all days in the monitored period. This builds a picture of the typical daily indoor conditions in the dwelling. From this representation, estimates of the heating system timings and set-points were determined as illustrated in Figure 5.

With the model fully defined, calibration was carried out by comparing simulation outcomes with monitored data for the pre-upgrade period. Calibration is automated via the Calibro tool (Monari and Strachan, 2017). When provided with a set of model parameters and the allowable ranges for their values, this tool utilises a statistical method to determine model input parameter values that give rise to the best fit with the monitored data. The best fit is the set of parameter values that maximises the goodness of fit between its internal statistical model and the monitored data. In this work, the thermostat set-point, heating system capacity, construction thermo-physical properties, and infiltration rate were the candidates for adjustment.

As these simulation models utilise stochastic occupancy models, there will never be an exact agreement between the observed and simulated fluctuations in temperature during the occupied hours that are caused by lighting, appliances, and the movement of people within the dwelling. To accommodate this issue, the procedure uses a 7-point calibration procedure (mean, standard deviation, minimum, 25th percentile, 50th percentile, 75th percentile, maximum). Where the absolute error between the monitored data and simulation output from the ESP-r model is minimised for each point. This ensures that the indoor temperature distributions are equivalent between the monitored real dwelling and the dwelling simulation. It also avoids the problems associated with the use of
RMSE, which can penalise a model with a single relatively large absolute error caused by, for example, a gain misaligned by only a single time-step.

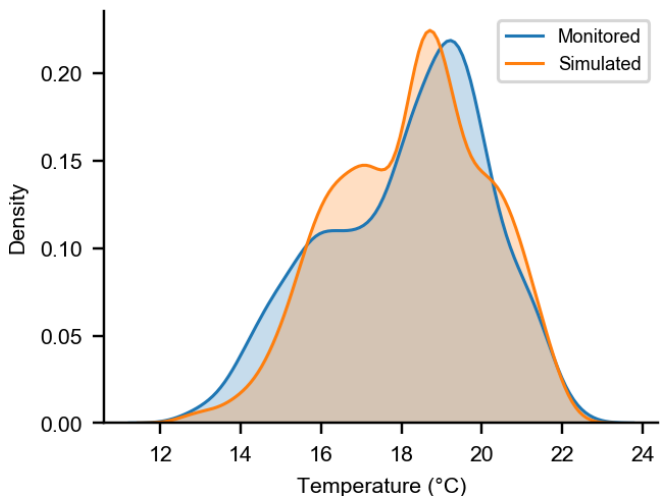

Figure 6: Probability density function comparison of indoor temperatures for a calibrated dwelling.

The 7-point calibration can be visualised by generating a probability density function from the monitored and simulated data. Figure 6 shows a comparison of a calibrated dwelling with the metrics provided in Table 2 .

Table 2: Example of calibrated model metrics.

\begin{tabular}{|c|c|c|c|}
\hline Metric & Monitored & Simulation & $\begin{array}{c}\text { Absolute } \\
\text { Error (\%) }\end{array}$ \\
\hline Mean & 18.1 & 18.2 & 1 \\
\hline Standard dev. & 2.0 & 1.9 & 5 \\
\hline Minimum & 12.6 & 12.7 & 1 \\
\hline 25\% Percentile & 16.7 & 16.9 & 1 \\
\hline Median & 18.5 & 18.5 & 0 \\
\hline 75\% Percentile & 19.6 & 19.6 & 0 \\
\hline Maximum & 22.4 & 22.0 & 2 \\
\hline
\end{tabular}

Figure 7 shows a comparison between a post-calibration simulation and monitored data for the temperature component of the calibration procedure, illustrating the improved match after the model calibration process.

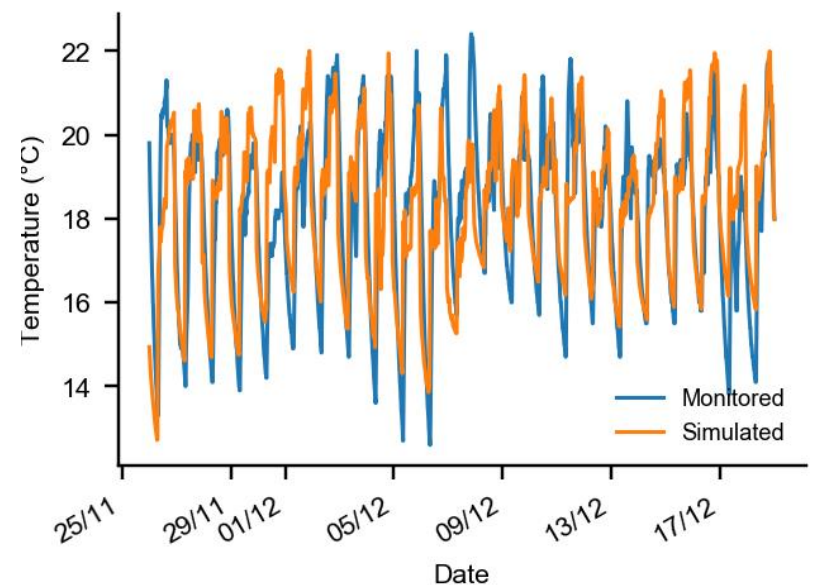

Figure 7: Comparison between post-calibration simulation predictions and monitored data for temperature.

In addition, the same procedure used to determine the heating system timings (Figure 5) can be used to compare the daily temperature profiles for the monitored and simulation data as shown in Figure 8. 
The calibrated model was subjected to annual simulations to determine the heating energy use. The model was then adapted to represent the proposed building upgrade and again subject to an annual simulation. The percentage difference between the two simulations is the theoretical heating energy saving potential associated with the proposed upgrade. Note that this is the best performance that can be attained assuming a fault-free upgrade and that occupant behaviour and heating system use remains the same post-update.

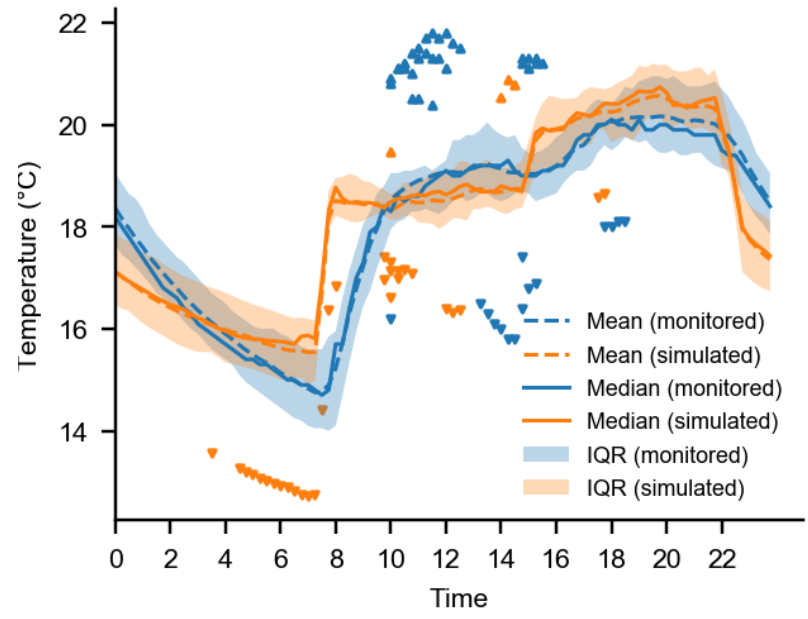

Figure 8: Statistical metrics of daily indoor temperatures for the monitored and simulated cases.

\section{Stock model selection procedure}

By using a specific combination of key parameters for each dwelling in the trial, an equivalent individual dwelling can be identified within the HUE database that represents its behaviour (here the information of Table 1 and data from site visits as described in the previous section). Each dwelling was identified by:

- house type (semi-detached, tenement, 4-in-block);

- year of build (1919-44/1945-64);

- number of storeys (1/2);

- air leakage (5 levels: 1 (low)-5 (high));

- heating system efficiency (low/med/high);

- heating control type (14 options);

- building thermal mass (low/high); and

- occupancy (5 levels: 1 (low)-5 (high)).

The relevant HUE model then gives the space heating requirements for that dwelling. This value corresponds to the annual space heating requirement pre-upgrade.

HUE incorporates a matrix of model variants that were simulated for a range of different contexts, e.g. local weather, air leakage properties, solar ingress, changes in occupancy patterns etc. to allow building performance to be established for these cases. The selection of the variant corresponding to the post-upgrade conditions uses the same parameters as listed above but with the amendment of enhanced construction, as judged by the equivalent $U$ value of the walls with external wall insulation applied.

The post-upgrade annual space heating requirements are then determined by 1) selecting the pre-upgrade model from the stock, 2) applying the modification to the wall construction properties and 3 ) reducing the air leakage by one level. The air leakage is reduced as external wall insulation upgrades typically increase the through-wall air tightness by negating the effects of mortar gaps, cracks in bricks/blocks/render etc. The newly selected model from HUE gives the space heating requirements for that dwelling post-upgrade.

\section{Results and discussion}

\section{Procedure outcomes}

Table 3 lists the benchmark savings for each monitored dwelling in the trial. These data demonstrate the large variation in anticipated benefit among the dwellings in the trial, justifying the rationale for case-by-case benchmarks.

Table 3: Energy performance benchmarks.

\begin{tabular}{|c|c|c|c|c|}
\hline \multirow[b]{2}{*}{ ID } & \multicolumn{2}{|c|}{$\begin{array}{c}\text { Benchmark savings } \\
(\%)\end{array}$} & \multirow{2}{*}{$\begin{array}{c}\text { Actual } \\
\text { savings } \\
(\%)\end{array}$} & \multirow[b]{2}{*}{ Category } \\
\hline & ICM & HUE & & \\
\hline AN2 & 14 & 17 & 70 & 4 \\
\hline AN3 & 14 & 16 & -4 & 1 \\
\hline CA4 & 23 & 32 & 18 & 0 \\
\hline CA5 & 16 & 33 & 18 & 2 \\
\hline CA6 & 16 & 33 & 17 & 0 \\
\hline CA7 & 24 & 25 & 3 & 1 \\
\hline CA8 & 23 & 32 & 60 & 4 \\
\hline DR1 & 14 & 40 & 19 & 2 \\
\hline DR2 & 23 & 40 & 26 & 0 \\
\hline DR4 & 22 & 41 & 6 & 3 \\
\hline DR5 & 16 & 40 & 8 & 3 \\
\hline DR6 & 22 & 39 & 10 & 3 \\
\hline SL3 & 25 & 46 & 4 & 1 \\
\hline SL4 & 16 & 48 & 23 & 0 \\
\hline SH6 & 15 & 32 & 8 & 1 \\
\hline SH7 & 15 & 32 & 40 & 2 \\
\hline SH8 & 15 & 33 & 41 & 0 \\
\hline
\end{tabular}

\section{Comparison of ICM benchmarks and actual savings}

From Table $3 \sim 29 \%$ of the upgrades (category 0) could be immediately signed-off as their energy performance was close to their ICM benchmark and a separate analysis confirmed acceptable indoor conditions. The remaining dwellings required further investigation. These latter dwellings fell into the following categories.

1. In $24 \%$ of the dwellings, the expected energy saving, compared to the benchmark, was not achieved. In these cases, the occupants had taken a large part of the insulation benefit as a higher standard of comfort.

2. $18 \%$ of the dwellings exceeded their benchmark energy savings, but exhibited low indoor temperatures for prolonged periods and low total energy use preand post-upgrade. This indicated that the occupants were not using their heating system to provide recommended indoor conditions. This could be a sign that the occupants are experiencing difficulties relating to fuel poverty.

3. $17 \%$ of dwellings had low energy saving compared to the benchmark, but had favourable indoor conditions pre- and post-upgrade. In these cases, it was not 
possible to determine whether behaviour changes or faulty installation was responsible for the discrepancy. A follow-on investigation was initiated by the Local Authority.

4. The final $12 \%$ of the dwellings demonstrated significant energy savings above the benchmarks. However, these results were based on a short period of monitored energy use data post-upgrade. The results were deemed unreliable in these cases.

\section{Comparison among benchmarks}

Overall, the benchmarks from the HUE models tend to over-predict the potential savings due to the building upgrade in comparison with the ICM models and the realworld performance. However, for $29 \%$ of the cases the ICM and HUE models demonstrated a good agreement between predicted performances.

It is believed that the reason for the over prediction in the majority of the cases is the use of the monitored dataderived heating profiles in the ICMs. These allow the ICMs to more accuracy capture the heating system timeof-use and set-points for the specific dwellings, which have a significant effect on the space heating use. Investigation of the monitored temperature data for the cases in which the ICMs and HUE models showed agreement were in dwellings which followed a more 'standard' heating profile with the heating remaining on during the actively occupied hours at approx. $21{ }^{\circ} \mathrm{C}$.

While HUE has the facility to select the heating control type (e.g. boiler thermostat or room thermostat), it lacks the ability to input on/off times and thermostat settings. Accounting for all potential on/off times and thermostat positions for domestic dwellings in a pre-simulated stock would be computationally expensive. However, future versions of HUE could incorporate a sub-set of the heating profiles generated in the construction of the ICMs in this work. The hypothesis being that in doing so HUE would be able to generate energy performance benchmarks in-line with those attained by individually calibrated models.

\section{Role of stock model benchmarks in future studies}

The use of pre-constructed stock models for generating benchmarks could have further uses than just being able to deliver more rapidly than an ICM. Consider each of the outcome categories discussed earlier.

Category 1: These outcomes assume that had the original comfort levels been maintained, the energy saving would have been achieved. This analysis could be quickly confirmed using stock model derived benchmarks by selecting a different heating profile from the future stock model.

Category 2: By selecting different heating profiles for both the pre- and post-upgrade selections from the stock could confirm this hypothesis.

Category 3: Using a future stock model with additional parameter diversity it would be possible to permute the parameters to identify possible causes based on the measured energy performance benchmark for that archetype.
In many of the cases that were immediately signed-off, the actual energy savings exceeded that of the theoretical best-case energy savings as determined by computer simulation. These results can also be attributed to changes in occupant behaviour. In one case, the average indoor temperature in the living area post-upgrade was lower than pre-upgrade, with minimum temperatures higher and maximum temperatures lower. This indicated that the occupants were using their heating system less after the upgrade. Such a reduction in heating system use could be because the home can retain heat for longer so that the operative temperature is the same as pre-upgrade even with a reduction in air temperature.

\section{Conclusions}

In the context of dwelling upgrades in Glasgow, the trial has shown that a low-cost monitoring approach can provide confirmation (or otherwise) of the efficacy of housing upgrades across a targeted estate. Outcomes from pre- and post-upgrade monitoring of internal/ external conditions and energy use were used to ascertain whether the upgrades were acceptable and to what extent the savings potential had been achieved.

Many cities are upgrading old housing stock, and in the project reported here, a large upgrade programme was underway in Glasgow. A sample set of dwellings was subjected to short-term low-cost monitoring, and an upgrade evaluation procedure was developed that utilised detailed building simulation of calibrated models. However, the drawback of the procedure was the inability to generate benchmarks rapidly. In addition, the generation of new benchmarks is required when there is a change in occupant behaviour post-upgrade.

To reduce the time and cost that are required for generation of individually calibrated models, corresponding models were selected from an existing presimulated set of models comprising a building stock model.

The results demonstrate that the stock model with its current level of parameter diversity is able to provide a reasonable agreement between benchmarks derived from ICM in $\sim 29 \%$ of the cases. If future versions can incorporate heating system time-of-use and a range of thermostat set-points it is hypothesised that the stock model could provide a reasonable agreement in the majority of cases. This would require the following developments.

- Incorporation of a set of monitored data-derived heating profiles into the stock models,

- Pre-simulation of a range of stochastic occupancy profiles.

- Re-calibration of ICMs with post-upgrade monitored data to confirm assesments on changes in occupant behaviour.

- Currently neither benchmark generation approaches include any faults in the dwellings such as disrepair to critical elements, urgent disrepair, rising damp, penetrating damp or condensation. These can be included in future in order to benchmark the penalty 
to energy performance due to such faults in the building fabric.

\section{References}

Allison J, Cameron G, Clarke J A, Cockroft J, Markopoulos A and Samuel A (2015) 'Confirming the effectiveness of insulation upgrades applied to Glasgow housing', Final report to Glasgow City Council for the TSB UK Future Cities Demonstrator project.

Clarke, J A (2001) Energy simulation in building design (2nd ed.). Oxford, UK: Butterworth-Heinemann.

Clarke J A, Johnstone C M, Kondratenko I, Lever M, McElroy L B, Prazeres L, Strachan P A, McKenzie F and Peart G (2004), 'Using simulation to formulate domestic sector upgrading strategies for Scotland', Energy and Buildings, 36, pp. 759-70.

Clarke J A, Ghauri S, Johnstone C, Kim J and Tuohy P G (2008) 'The EDEM Methodology for Housing Upgrade Analysis, Carbon and Energy Labelling and National Policy Development', Proc. eSim '08, Quebec.

The Electricity and Gas (Energy Companies Obligation) Order 2012 (No. SI 2012/3018). Retrieved from http://www.legislation.gov.uk/uksi/2012/3018/ pdfs/uksi\{\_\}20123018\{\_\}en.pdf

Energy Saving Trust (2017) Home Analytics. Retrieved from

http://www.energysavingtrust.org.uk/scotland/b usinesses-organisations/data-services/homeanalytics

Flett G and Kelly N (2016) 'An occupant-differentiated, higher-order Markov Chain method for prediction of domestic occupancy', Energy and Buildings, 125, pp. 219-230.

Flett G and Kelly N (2017) 'A disaggregated, probabilistic, high resolution method for assessment of domestic occupancy and electrical demand', Energy and Buildings, 140, pp. 171-187.

Harrison H, Mullin S and Reeves B (2004), Nontraditional houses: Identifying non-traditional houses in the UK, p. 958.

Kavgic M, Mavrogianni A, Mumovic D, Summerfield A, Stevanovic Z and Djurovic-Petrovic M (2010) 'A review of bottom-up building stock models for energy consumption in the residential sector', Building and Environment, 45(7), pp. 1683-1697.

Monari F and Strachan P (2017) 'CALIBRO: an R package for the automatic calibration of building energy simulation models', Proceedings of the 15th IBPSA Conference, San Francisco, CA, USA, Aug. 79, 2017.

MRUK (2016) Building a Future City - Evaluation Report. Glasgow, UK: Glasgow City Council.
Retrieved from http://futurecity.glasgow.gov.uk/reports/12826 M_FutureCityGlasgow_Evaluation_Final_v10.0.pdf

Scottish Government (2016a) Home Energy Efficiency Programmes for Scotland - Delivery Report 2015/16. Edinburgh, UK: The Scottish Government. Retrieved from https://beta.gov.scot/publications/homeenergy-efficiency-programmes-scotlandsummary-delivery-report-201516/documents/00524125.pdf

Scottish Government (2016b) Scottish Index of Multiple Deprivation (SIMD) 2016 [Dataset]. Edinburgh, UK: The Scottish Government. Retrieved from http://www.gov.scot/Resource/0051/00510565. xlsx

Scottish Government (2018) SHCS Local Authority Analysis 2014-2016 [Dataset]. Edinburgh, UK: The Scottish Government. Retrieved from http://www.gov.scot/Resource/0053/00532143. xlsx 